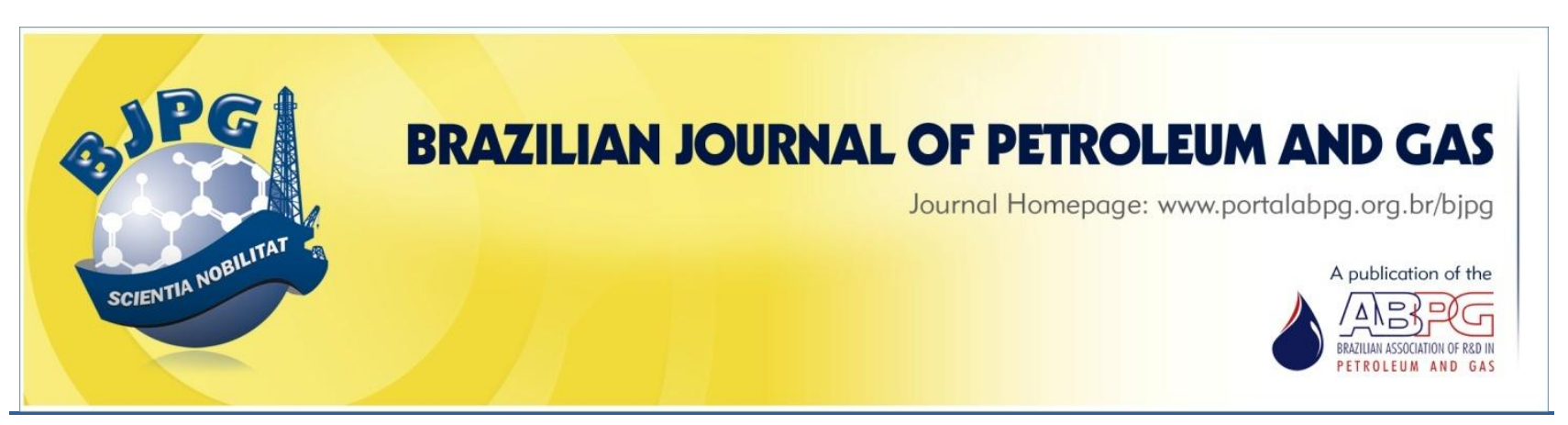

\title{
FACTORS THAT AFFECT CRUDE OIL VISCOSITY AND TECHNIQUES TO REDUCE IT: A REVIEW
}

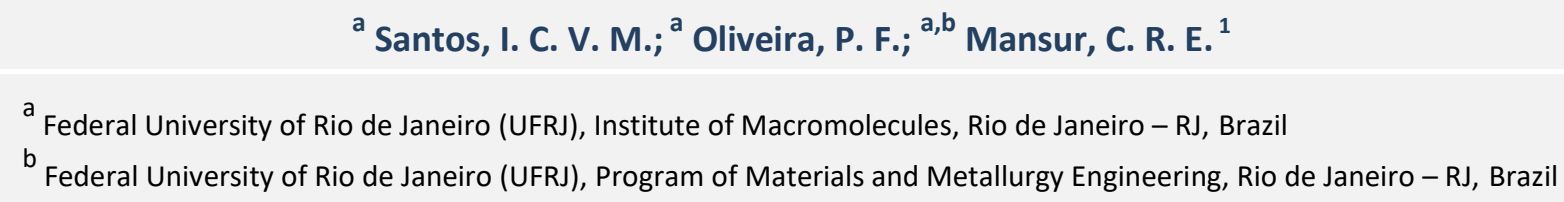

\section{ABSTRACT}

During oil extraction, the high viscosity of crude oil cause major problems, affecting negatively the oil production rate. Many studies have focused on evaluating the properties of different crude oil grades and their production techniques. The main causes of high viscosity are the presence of solids and high concentrations of heavy fractions and the formation of water-in-oil (W/O) emulsions. This paper discusses the mechanisms that seek to reduce the viscosity of oil containing high concentrations of heavy fractions, the mechanisms of formation and destabilization of emulsions, and the use of polymers in technologies to reduce viscosity, mainly by applying emulsion viscosity reducers (EVRs).

\section{KEYWORDS}

petroleum; viscosity; emulsion; heavy oil; extra heavy oil

\footnotetext{
${ }^{1}$ To whom all correspondence should be addressed. Address: Universidade Federal do Rio de Janeiro (UFRJ), Centro de Tecnologia, BI. J, Avenida Horácio Macedo, 2030, Cidade Universitária, Ilha do Fundão, Rio de Janeiro - RJ, Brasil.

ZIP Code: 21941-598 | e-mail: celias@ima.ufri.br doi:10.5419/bjpg2017-0010
} 


\section{INTRODUCTION}

Global demand for oil has been increasing over the past two decades (Ghanavati et al., 2013). Just in the last quarter of the 20th century alone, it registered an increase of about $1 \%$ a year. This pace accelerated substantially with the start of the $21^{\text {st }}$ century, mainly because of growing demands from emerging countries like China and India. In 2009, global oil demand was $1.8 \%$ higher than the previous year, despite the global economic slump caused by the subprime mortgage crisis. The International Energy Agency (IEA) and the World Energy Council (WEC) agree that, based on current projection, the demand will grow $66 \%$ by 2030 . International studies also predict that in the next 20 years, at least $80 \%$ of the world's energy needs will be supplied by oil, natural gas, and coal (Martinez-Palou et al., 2011). Therefore, despite efforts to develop alternative energy sources, hydrocarbons will continue playing the leading role in satisfying global energy demand. However, the consumption of conventional light oils has resulted in declining reserves of these resources (Saniere et al., 2004). As fossil fuels will remain to be the main energy source for the coming decades, there is an urgent need to exploit alternative fossil resources (Dusseault \& Shafiei, 2011). Therefore, substantial efforts have been devoted to the effective production of heavy and extra-heavy oils from reservoirs (i.e., natural bitumen or oil sands), which account for ca. $70 \%$ of total world oil reserves (Dusseault \& Shafiei, 2011).

Crude oil is a complex mixture of thousands of compounds with numerous functional groups, consisting mainly of simple hydrocarbon species, and the variation in its composition gives it different properties. Petroleum is characterized in terms of the contents of the fractions denominated by saturated, aromatic, resins, and asphaltenes (SARA). These fractions are separated from petroleum based on their polarity, using solvents with different polarities and the adsorption on active surfaces, such as silica (Varfolomeev et al., 2016).

Saturates are essentially non-polar and free of double bonds. Aliphatic hydrocarbons and alicyclic hydrocarbons are part of this classification and they constitute the lightest fraction of the oil. Aromatics are compounds containing one or more benzene rings, which may contain aliphatic chains and/or naphthenic rings attached to the benzene ring (Castro \& Vazquez, 2009). Resins are defined as the fraction of oil soluble in light alkanes. They have aromatic and polar characteristics, besides having in their structure heteroatoms, such as nitrogen and oxygen (Ashoori et al., 2017; Muraza \& Galadima, 2015).

Asphaltenes are defined as the fraction of oil insoluble in $\mathrm{n}$-alkanes (such as n-pentene and $\mathrm{n}$ heptane) and soluble in aromatic solvents (benzene and toluene) (Asomaning, 2003, Garcia-Olvera et al., 2016). In addition, these are the components of higher polarity and higher molar mass present in the oil. They have a great structural complexity originated from polycondensed aromatic rings containing alkyl radicals of different sizes and functional groups formed by oxygen, nitrogen and sulfur elements, as well as metals such as vanadium, nickel, and iron (Ovalles et al., 2016).

Asphaltenes are the main components of heavy oil and bitumen. Reservoirs show significant geological differences in producing oils with different SARA proportions and sulfur content. For example, high sulfur heavy oils mostly exist in North America, South America, and Middle Eastern countries (Sheu et al., 1991b).

Heavy or extra-heavy oils are highly viscous oils that cannot easily flow to production wells at normal reservoir conditions. The definition of "heavy" is based on the density or specific gravity, which is higher than that of lighter oils (i.e. conventional oils) (Martinez-Palou et al., 2015).

Gravity and viscosity are the two standards used to classify light, heavy, and extra-heavy oils, which are exemplified below: (1) Light oil: ${ }^{\circ} \mathrm{API}>22$, viscosity < $100 \mathrm{cP}$, density $<934 \mathrm{~kg} / \mathrm{m}^{3}$; (2) Heavy oil: ${ }^{\circ} \mathrm{API} 10-22$, viscosity $>100 \mathrm{cP}$, density 934$1000 \mathrm{Kg} / \mathrm{m}^{3}$ and (3) Extra-heavy oil (bitumen): ${ }^{\circ} \mathrm{API}$ $<10$, viscosity > $10.000 \mathrm{cP}$ and density > 1000 $\mathrm{Kg} / \mathrm{m}^{3}$ (Guo et al., 2016).

Besides viscosity, density, and ${ }^{\circ} \mathrm{API}$, heavy and extra heavy oils also have other physical and chemical properties that are very different than those of conventional crudes, such as higher concentrations of heavy metals, high carbon/hydrogen $(\mathrm{C} / \mathrm{H})$ ratios, and high heteroatom contents (Martinez-Palou et al., 2011; Saniere et al., 2004). These oils are less valuable because of the greater difficulty of achieving water- 
oil separation, transporting and refining (Kelesoglu et al., 2012). They are highly viscous, and cannot easily flow to production wells at normal reservoir conditions, since their consistency varies from a paste to a solid at room temperature, with viscosities ranging from $10^{2} \mathrm{cP}$ to more than $10^{5} \mathrm{cP}$ at room temperature. Generally, a crude oi with viscosity < $400 \mathrm{cP}$ has the maximum desired pipeline viscosity (Hasan et al., 2010). Several factors can influence this viscosity, such as high concentration of heavy fractions such as asphaltenes and presence of water-in-oil (W/O) emulsions (Kessick \& Denis, 1982).

The formation of $\mathrm{W} / \mathrm{O}$ emulsions can reduce substantially oil production rates because of the high viscosity of the emulsions, which increase with the water content until reaching the phase inversion point (PIP). It is important to know both the emulsion viscosity and the phase inversion point to make proper decisions on the size of lines and equipment and to evaluate production strategies (Kelesoglu et al., 2012). The presence of inorganic solids in crude oil can also cause complications for transportation. If the size of these particles is sufficiently small (a few microns or less), they can be adsorbed on the heavy fractions, such as resins and asphaltenes. These aggregates then tend to migrate to the water-oil interface, forming extremely stable emulsions and making the oil highly viscous, both because of the quantity of emulsion and the quantity of solids (Abdel-Raouf, 2012).

This report intends to review the recent progress in the factors that affect crude oil viscosity, and aims to provide systematic knowledge about the techniques to reduce it.

\section{THE INFLUENCE OF COMPOSITION ON CRUDE OIL VISCOSITY}

According to some authors (Yudin et al., 1998; Fenistein et al., 1998; Sheu et al., 1991a; Acevedo et al., 1999), crude oils can be divided into noncolloidal liquids, maltenes, and asphaltenes; the last being a dark brown powder that can agglomerate and increase the oil viscosity.

In 2001, Hénaut studied the influence of asphaltene concentration on the viscosity of heavy crudes. The tests were conducted in maltene sample containing quantities of asphaltenes ranging from 0 to $20 \%$ by mass. The author performed a scan in a sheer stress range of 0.03 $596 \mathrm{~Pa}$ at $20{ }^{\circ} \mathrm{C}$. The results showed that all the samples behaved as Newtonian fluids, and the viscosity increased with rising asphaltene concentration. For example, the viscosity of the maltenes was about $20000 \mathrm{cP}$ while that of the sample containing $17 \%$ asphaltenes reached 600 000 cP (Hénaut et al., 2001).

According to Argiller et al. (2002), rheological measurements of some mixtures of maltenes and asphaltenes revealed that, above a critical asphaltene concentration ( $10 \%$ by weight), these components not only dramatically increase the viscosity, they also intensify the elastic character of the mixture.

Ghanavati et al. (2013) analyzed the effect of asphaltene quantity on the viscosity of a dehydrated heavy oil. For this purpose, an initial sample of crude oil was obtained from one of Iran's main fields. The asphaltenes, composing $14.9 \%$ of the weight, were extracted with hexane, to obtain 10 asphaltene-free samples, called maltene. Then different concentrations of asphaltenes were added to these samples. The results showed that in the diluted region (the samples with low asphaltene content) the increase in viscosity was relatively linear with rising asphaltene concentration, and it was not highly dependent on temperature. According to the authors, this was due to the fact that the asphaltene particles are spaced far apart, so their interactions are weak. With increasing asphaltene concentration, the viscosity started to deviate from linear and increased more sharply than in the diluted region at the same temperature. This was due to the increase in the quantity of asphaltene particles, which increases their interactions due to presenting a closer spacing than in the diluted region. After the middle region, the relative viscosity increased more rapidly with an increase in asphaltene concentration, becoming the most evident tendency. Besides this, the separation of the relative viscosity at different temperatures is an indication of the stronger influence of temperature in this region.

Luo and Gu (2005) also studied the effect of asphaltene concentration on the viscosity of reconstituted heavy oil samples at different 
temperatures. The viscosity of the reconstituted heavy oil sample with $14.5 \%$ by weight of asphaltenes was $23199 \mathrm{cP}$ at $23.9^{\circ} \mathrm{C}$, while that of the reconstituted sample without asphaltenes (i.e., only maltenes) was only $767 \mathrm{cP}$. According to the authors, this means that the high viscosity of the heavy oil tested was caused mainly by the asphaltenes, and the viscosity increased sharply when the asphaltenes started to flocculate.

\subsection{Methods for reducing crude oil viscosity}

Historically, the demand for heavy and extraheavy crudes has been low because their high viscosity and complex composition make them difficult and costly to extract, transport and refine. Overcoming these challenges requires significant technological advances. Different methods have been used or studied to reduce the viscosity of heavy and extra-heavy oils and thus improve their flow through pipelines. Among these methods are: the dilution with light oils or alcohols, heating of production lines or the oil itself, use of emulsion viscosity reducers, viscosity reducing additives of the oil in aqueous surfactant solution (Azodi \& Nazar, 2013; Sanchez \& Zakin, 1994). The current status of these techniques is reviewed below.

\subsubsection{Dilution of crude oil with light oils or alcohols}

Dilution is one of the oldest and most popular methods to reduce the viscosity of heavy crudes. This technique consists of adding lighter liquid hydrocarbons to the heavy oil. This is mainly used to facilitate passage in pipelines. A solvent in the proportion of $20-30 \%$ is often sufficient to avoid high-pressure drops or the need for high temperatures. Besides this, the dilution method can facilitate dehydration and desalinization of these oils. That technology is the solution used most frequently for this purpose, but it can require large investments for pumping and pipeline equipment due to the increased volume carried and the need to separate the solvent from the oil at some points (Martinez-Palou et al., 2011).

Yaghi and Al-Bemani (2002) observed that a mixture of heavy and light oils in a proportion of 7:3 had viscosity of 1000 and $300 \mathrm{cP}$ at temperatures of 30 and $50{ }^{\circ} \mathrm{C}$, respectively, versus $15000 \mathrm{cP}$ at $20^{\circ} \mathrm{C}$ for the initial heavy oil.
Hasan et al. (2010), studied different viscosity reduction techniques in a heavy oil sample, with the main objective of investigating the rheological properties of the treated oil samples. The first and second techniques consisted of mixing the heavy oil with alcohol and light oil, respectively, at different temperatures. The viscosity results of the mixtures of heavy crude with $10 \%$ and $20 \%$ alcohol showed that these fluids had a similar rheological behavior to the pure oil, but the viscosity values declined drastically, from 10000 to $2000 \mathrm{cP}$ (system with 10\% alcohol) and from 10000 to 9 $500 \mathrm{cP}$ (system with $20 \%$ alcohol). According to the authors, the alcohol acted as a diluent and the viscosity declined due to the interactions of the hydroxyl groups with some functional groups present in the asphaltenes. The second set of experiments involved mixing this oil with a light oil sample, having viscosity of around $300 \mathrm{cP}$. The objective was to obtain an oil sample with lower viscosity and density to enable transport through pipelines. The samples containing alcohol and light petroleum were prepared simply by mixing these components with the heavy oil. The results obtained with $10 \%$ and $20 \%$ light oil showed that these fluids had a rheological behavior similar to that of the pure heavy oil. The viscosity fell from 10 000 to $1200 \mathrm{cP}$ for the mixture with $10 \%$ light oil and from 10000 to $350 \mathrm{cP}$ for the $20 \%$ light oil mixture (which was 26 times lower than the viscosity of the pure oil). The authors concluded that this technique presented better results that the other two, since it was possible to obtain viscosity of $350 \mathrm{cP}$ by adding $20 \%$ light oil to the heavy crude.

Hénaut et al. (2007) investigated the use of dimethyl ether (DME) as solvent to adjust the viscosity and reduce pressure during transport. A major advantage of using this process is that the recovery of DME at the refinery is easier than for other solvents.

Alcohols are also being studied as solvents, especially pentan-1-ol, which is much more effective in reducing the viscosity of heavy crude than kerosene, due to the interactions generated by the hydrogen bonds of the hydroxyl groups with the asphaltenes. High polarity or high degree of hydrogen bonding of the solvent produces greater reduction of the viscosity of crude oil. However, solvents with many hydrogen bonds generally are more viscous than the hydrocarbons. Only polar 
solvents with few hydrogen bonds cause a significant reduction in the viscosity of crude oil (Plasencia et al., 2013).

Furthermore, the dilution option faces some challenges, since any change in the oil's composition can affect the necessary oil/solvent proportion. Naphtha or light oils are interesting alternatives due to their high API gravity and their efficiency in diluting heavy oils. However, the mixture can alter the stability of the asphaltenes and cause them to flocculate and precipitate, in turn, blocking gas pipelines. Further studies are necessary to understand the aggregation and flocculation of asphaltenes as well as the crystallization and deposition of waxes (MartinezPalou et al., 2011).

From an economic standpoint, the cost of the light fractions used as solvents may not be offset by the higher value of the treated heavy oil. This requires careful economic analysis of the heavy and light oils involved in the process.

\subsubsection{Heating of production lines or the crude oil}

Heating is the second most commonly used method to reduce the viscosity of heavy oils carried through pipes. The basis of this method is that viscosity declines with rising temperature, making it easier to pump oil. It is therefore important to heat the oil to a temperature at which the viscosity is substantially reduced. The principle is to preserve the high temperature at which the oil is extracted by insulating pipes. Insulation options include burying traditional pipelines to preserve heat. However, external heating is almost always necessary due to heat losses caused by the slow flow. This requires reheating at pumping stations through direct heaters. Besides this, traditional pipelines can be operated with low vapor pressure, near environmental pressure, to maximize their capacity (Ghannam \& Esmail, 2006).

A disadvantage of the heating of production lines is the high costs for long distance operations. This is aggravated in offshore operations because of the cooling exerted by the seawater and the difficulty of installing and maintaining submerged pumping and heating stations (Hansan et al., 2010).

\subsubsection{Mixtures with chemical viscosity- reducing additives}

Xie et al. (2001) investigated the effects of oilbased and water-based chemicals. They found that the oil-based additive studied was a good viscosity reducer for crude oils with low or medium viscosity. Nevertheless, they found that waterbased additives were very good viscosity reducers for crude oil with high viscosity.

Several studies have utilized chemical additives as viscosity reducers in crude oil applications, in particular to enhance heavy crude oil recovery (Kuzmic et al., 2008; Soni et al., 2010).

Chemical additives are highly selective, meaning that many additives lack effectiveness for a particular crude oil. To choose or develop the best additive requires knowing the composition of the oil in question. For example, some very viscous heavy oils from Mexico contain high concentrations of asphaltenes ( $>8 \%$ by weight), low paraffin levels, and appreciable quantities of sulfur $(>1.9 \%$ by weight), nickel, and vanadium (Castro \& Vazquez, 2009).

Castro et al. (2011) studied the effect of composition and molar mass of six thermopolymers prepared from styrene (S), $n$-butyl acrylate (BuA), and vinyl acetate (VA) on the apparent viscosity of a heavy oil from the Gulf of Mexico. The oil had the following physical characteristics: API density $=15.82$; water content $=0.10 \%$; kinematic viscosity at $25{ }^{\circ} \mathrm{C}=2984.97$ $\mathrm{mm}^{2} \mathrm{~s}^{-1}$; and asphaltenes content $=19.92 \%$. The thermopolymer solutions were prepared at $20 \%$ $\mathrm{m} / \mathrm{m}$ in toluene and were applied in the oil at a dosage of $1000 \mathrm{ppm}$.

The efficiency of a polymer as a viscosity reducer of dehydrated heavy oils depends mainly on the thermodynamic affinity of the segments of its chain with the oil's components (saturates, resins, asphaltenes, and aromatics). The authors observed that all the thermopolymers reduced the apparent viscosity of the crude oil and that this reduction depended on the molar mass of the thermopolymer used as the additive.

Polymer samples with mutually similar compositions, but very different molecular masses, exhibited practically the same efficiency as viscosity reducers of heavy oil. The same behavior 
was observed when comparing the curves of the oil containing samples with different molar masses and different compositions, which exhibited the same rheological behavior after a shear rate of $2 \mathrm{~s}^{-1}$. Polymers with composition rich in $\mathrm{S}$ were the most efficient as viscosity reducers. Analysis of the influence of the composition of the thermopolymers used as viscosity reducers on the rheological behavior of the crude oil revealed that the higher the $\mathrm{S}$ content was, the greater the viscosity reduction was, regardless of the polymer's molar mass.

The efficiency of these thermopolymers as flow enhancers can be explained by the following structural effects: (1) the presence of $S$ allows better interactions with the asphaltenes, resins, and other compounds due to its aromatic nature; (2) the presence of VA gives a polar functionality to the thermopolymer's structure, favoring the attraction forces between additive and resins; and (3) the presence of BuA promotes interactions between the thermopolymers and the paraffins in the crude oil.

Junaki et al. (2012) developed an ionic additive named IRAN91. The effectiveness of this additive in reducing the viscosity of heavy oil was investigated by using samples from the Marun oil field, Bangestan reservoir. They found that the presence of the ionic additive resulted in a reduction of heavy oil viscosity up to $64 \%$.

\subsubsection{Formation of heavy crude oil emulsions in water $(\mathrm{O} / \mathrm{W})$}

Oil in water $(\mathrm{O} / \mathrm{W})$ emulsions can be formed containing high oil percentages, sufficient to make the process economically attractive, especially because the diluent (water) is inexpensive. The viscosity of these emulsions is much lower than that of the crude oil, relatively independent of the oil type used (Hansan et al., 2010).

Surfactants are used as emulsifiers by stabilizing the droplets of the dispersed phase within the continuous phase to avoid their coalescence, generating stable $\mathrm{O} / \mathrm{W}$ emulsions with low interfacial tensions. By using surfactants to form an $\mathrm{O} / \mathrm{W}$ emulsion, the crude oil can be suspended as micro droplets stabilized in a continuous aqueous phase, thus, reducing the apparent viscosity. This can be a good alternative compared to using diluents or heating for transporting these oils in pipelines. Crude oil emulsions have a pseudoplastic or shear-thinning behavior, meaning that the viscosity declines as the shear rate increases. The main difficulties of using this technique are the choice and cost of the surfactants used in the emulsion. Not only must the surfactant be able to stabilize the emulsion during transport, the cost of separating the oil and water phases when the fluid reaches its destination must not be too high (Langevin et al., 2004; Sullivan \& Kilpatrick, 2002).

Many studies have reported the rheological characterization of emulsions (Dan \& Jing, 2006; Farah et al., 2005). In a recent study, Hoshyargar and Ashrafizadehs (2013) found that the rheology of crude oil emulsions is affected by temperature, $\mathrm{Na}_{2} \mathrm{CO}_{3}$ concentration (component used to stabilize the emulsion), $\mathrm{NaCl}$ concentration (salinity of continuous phase), oil volume fraction $(\phi)$, and number of homogenizer revolutions. The emulsification method resulted in a reduction of crude oil viscosity by $90-99 \%$. The predictions were made using the Herschel-Bulkley model in all cases. The optimum flow conditions were reported as $\mathrm{T}=$ $25{ }^{\circ} \mathrm{C}, \mathrm{Na}_{2} \mathrm{CO}_{3}$ concentration $=2,000 \mathrm{ppm}, \mathrm{NaCl}$ concentration $=5,000 \mathrm{ppm}, \phi=0.7$, and revolution $=22,500$.

Hasan et al. (2010) investigated the dilution of a viscous crude oil as described earlier. They also prepared an emulsion with crude oil as the dispersed phase, and an aqueous solution of a commercial nonionic surfactant (Triton X-100 - 4 octylphenol polyethoxylate) as the continuous phase, at a concentration of $0.1 \%$. The emulsions were prepared by adding the aqueous phase to the heavy oil under stirring. The initial tests of viscosity versus shear rate for the crude oil at different temperatures showed a pseudoplastic behavior. The authors also noted that the difference in viscosity of these samples was greater at lower shear rates. The explanation given was that, as the temperature increases, the heavy oil fractions with high molar mass, such as asphaltenes, resins and waxes, among others, do not have a chance to agglomerate and form aggregates, so the oil's viscosity is reduced. Two different aqueous solution concentrations of the surfactant were tested $(10 \%$ and $20 \% \mathrm{v} / \mathrm{v})$, in the temperature range of $25-75^{\circ} \mathrm{C}$. At $25^{\circ} \mathrm{C}$, the viscosity values of the emulsions were lower than those of the crude oil, by $20 \%$ for the emulsion prepared with $10 \%$ aqueous solution and by $35 \%$ for the $20 \%$ solution. 
The authors also observed two distinct regions of the curves obtained by plotting viscosity in function of shear rate: the first region, at a shear rate of up to $500 \mathrm{~s}^{-1}$, where the viscosity of the emulsions had strong pseudoplastic behavior; and the second region, with shear rate of $500 \mathrm{~s}^{-1}$, where the emulsions behaved as Newtonian fluids. For high shear rates, all the curves clustered together, forming a "master" curve, indicating that the viscosity became independent of the shear rate and temperature.

Langevin et al. (2004) concluded that emulsion behavior is controlled largely by the properties of the adsorbed layers that stabilize the crude oilwater surface, and that emulsions with small size of dispersed droplets and a narrow particle size distribution have high viscosities and large residence time.

Indeed, bitumen (highly viscous crude oil) droplets in water have the same effect as other types of emulsions. This is because the viscosities of bitumen and water are very far apart. At room temperature, the viscosities of bitumen and water are $7000000 \mathrm{cP}$ and $1 \mathrm{cP}$, respectively. Other researchers support their findings, suggesting that dispersing bitumen in water is an efficient way to reduce the viscosity of fluids. Similar to crude oil emulsions, bitumen emulsions show shear thinning non-Newtonian behavior. The influence of shear rate on the viscosity increases as the concentration of the dispersed phase increases (Sullivan \& Kilpatrick, 2002; Nunez et al., 2000).

Making oil in water emulsion markedly diminishes oil viscosity. However, restoration of original hydrocarbon by breaking the emulsion is a subject of controversy (Martinez-Palou et al., 2011). In addition, choosing the best surfactant for a given oil and aqueous phase depends on their composition. Most importantly, surfactants are expensive materials and economic considerations may pose limitations on the amount of surfactant used (Sheng, 2015).

\section{THE INFLUENCE OF EMULSION FORMATION ON CRUDE OIL VISCOSITY}

At various times during oil production, mechanical energy is transmitted to the production fluids, causing the formation of emulsions. The lifting phase is the moment when the fluid is subjected to shear forces and pressures generated, for example, by electrical submersible pumps or gas lift (Allenson et al., 2011).

Researchers in the 1970s (Haeght \& Ellingsen, 1977; Wang \& Huang, 1979) concluded that the primary reason leading to emulsion formation was the increase in turbulence or mixing energy. According to Schubert and Armbruster et al., in 1992, turbulence plays an important role in the distribution and mixing of the phases during pipeline flow of water/oil systems.

The presence of emulsions during production of crude oil is one of the main factors that influence its viscosity. Pure hydrocarbons are not able to form stable emulsions with water or brine. However, due to the presence of natural surfactants in the oil and the shear that occurs during the extraction process, there is a tendency for emulsions to form. Among these surfactants are asphaltenes, resins, and naphthenic acids, which are amphiphilic molecules that have an interfacial activity. These compounds contain atoms of oxygen, nitrogen and sulfur in the form of carboxylic acid, phenol, amide, alcohol, amine, and mercaptan, among others (Allenson et al. 2011). The molecules have a wide range of chemical structures, molar masses and hydrophilic-lipophilic balance (HLB) values, and can interact and/or reorganize at the water-oil interface. Petroleum emulsions can also contain solids and gases (Fingas \& Fieldhouse, 2009; Maia Filho et al., 2012).

Under most oil production conditions, it is common to observe emulsions having water as the discontinuous (or internal) suspended phase and oil as the continuous (or external) phase (i.e., water-in-oil or W/O emulsions). It is also possible for oil-in-water water (O/W) emulsions to form, or even more complex ones composed of oil in water in oil (O/W/O), called multiple emulsions (Sefton \& Sinton, 2010).

These emulsions cause a considerable increase in the apparent viscosity and pseudoplastic behavior of crude oil, meaning that the viscosity declines with the shear rate. Due to difference of the internal microstructures, it is hard to predict the viscosities of these emulsions and their rheological properties with any precision (Wang et al., 2013). 
Ariffin et al. (2016) investigated the rheological behavior of light crude oil emulsion, particularly the viscosity behavior. Experimental results indicate that the viscosity of the emulsion decreases from 0.819 to 0.0466 Pa.s as the temperature increases from 20 to $90^{\circ} \mathrm{C}$. In addition, increasing the water volume fraction from $20 \%$ to $40 \%$ results in higher viscosity and characterized greater elasticity. The emulsion viscosities were significantly influenced by the shear rate, temperature, and water content.

Li et al. (2015) performed an experimental study of the influences of the temperature and water fraction on the elastic modulus, loss modulus, and loss angle. Their studies revealed that, increasing the temperature or reducing the water fraction, the gel structure could be weakened. This is reflected by the presence of a narrower linear viscoelastic region and lower values of the elastic modulus and loss modulus.

Besides increased oil viscosity, emulsions can cause other problems, such as corrosion and deposition of salt in pipelines and refining equipment, impairment of desalinization and dehydration (processes applied before refining), higher transport and storage costs, and catalyst poisoning (Al-Yaari et al., 2015).

Various factors can contribute to the viscosity of emulsions, such as oil viscosity, water viscosity, water concentration, temperature, droplet size and size distribution, quantity of solids in the oil, and shear rate. At low water cut, when the emulsions are diluted, the hydrodynamic forces during collision of the droplets govern the rheological behavior. As the water cut increases, meaning that the emulsion system is more concentrated, flow resistance can be induced by the deformation and rearrangement of the structures of the network of thin liquid films between the droplets (Plasencia et al., 2013). This flow resistance becomes more frequent as the concentration of water rises, caused by the presence of water in the formation (which tends to rise as the well ages due to depletion of the oil) and/or injection of water to increase pressure in the reservoir (Shecaira et al., 2002).

The emulsion's viscosity also depends on the quantity of water emulsified in the oil. The apparent viscosity of the emulsion increases when the water percentage increases, as the fluid is extracted, until a maximum value is reached. After reaching this high point, the viscosity starts to decline if more water is added to the system. This drop is due mainly to the presence of free water and/or the formation of inverse emulsions (O/W). The point at which this phenomenon occurs is called the phase inversion point (PIP) (Allenson et al., 2011).

Good knowledge of the oil's composition is necessary to take the proper measures to control the formation of emulsions in all production phases (Langevin et al., 2004). Laboratory studies have indicated that the quantity of water that can be emulsified depends on the crude oil's composition. Crude oils can form emulsions with between 40 to $70 \%$ brine before reaching the phase inversion point (Allenson et al., 2011).

Duan et al. (2010) studied the factors that affect the PIP of emulsions obtained from three heavy oil samples with different densities and viscosities. They found that, in general, the higher the density and viscosity of the heavy oil sample was, the lower the PIP was. This occurred because the content of natural surfactants (such as asphaltenes, resins and organic acids) in heavier oil is higher, causing more surfactant molecules to adsorb at the oil-water interface, increasing the thickness and strength of the film. The resulting conditions were more favorable to the dispersion of water droplets.

Anisa and Nour (2010) produced W/O emulsions from three crude oils having different characteristics of API gravity and viscosity. The objective of the study was to assess the effects of temperature and effects of stirring speed to the viscosity and the average droplet diameter of W/O emulsions. The emulsions were prepared by adding water to a mixture of oil and a nonionic surfactant at a concentration of $0.1 \%$, under stirring at 1500 $\mathrm{rpm}$ for 5 minutes. The authors observed, by means of micrographs, that the system containing the highest water concentration $(50 \% \mathrm{v} / \mathrm{v})$ had the largest droplets (average diameter of $26.60 \mu \mathrm{m}$ ) and these were nearer to each other with a more fragile interfacial film, rendering the system unstable and thereby enhancing coalescence. The droplets in the emulsion with the lowest water content $(20 \% \mathrm{v} / \mathrm{v})$ had an average diameter of $20.76 \mu \mathrm{m}$, and were spaced further apart with more rigid films, generating an unstable system. 
Table 1. Classification of water-in-oil mixtures.

\begin{tabular}{|c|c|c|c|}
\hline $\begin{array}{c}\text { Stable W/O } \\
\text { emulsions }\end{array}$ & $\begin{array}{l}\text { Mesostable W/O emulsions } \\
\text { (displays the properties } \\
\text { between stable and unstable } \\
\text { emulsion) }\end{array}$ & Entrained water-in-oil & $\begin{array}{c}\text { Unstable water-in-oil } \\
\text { (not characterized as } \\
\text { emulsion) }\end{array}$ \\
\hline $\begin{array}{l}\text { - remains intact for at } \\
\text { least four weeks } \\
\text { - appears as a brown } \\
\text { or reddish semi-solid } \\
\text { material } \\
\text { - has an average } \\
\text { water content of } \\
\text { about } 80 \% \text { and stays } \\
\text { about the same after } \\
\text { a week } \\
\text { - viscosity } 15 \text { - } 10000 \\
\mathrm{cP} \\
\text { - density } 0.85 \text { - } 0.97 \\
\mathrm{~g} / \mathrm{mL} \\
\text { - asphaltene-to-resin } \\
\text { ratio } 0.74 \\
\text { - apparent viscosity, } 1 \\
100 \mathrm{cP} \text { at day of } \\
\text { emulsion formed and } \\
1500 \mathrm{cP} \text { a week later }\end{array}$ & $\begin{array}{l}\text { - remains unbroken for less } \\
\text { than three days, and are } \\
\text { separated into water and free } \\
\text { oil in around one to three days } \\
\text { - appear as black or brown } \\
\text { liquid } \\
\text { - has an average water content } \\
\text { of about } 70 \% \text { and reduced to } \\
\text { around } 30 \% \text { after one week } \\
\text { - viscosity } 6 \text { - } 23000 \mathrm{cP} \\
\text { - density } 0.84 \text { - } 0.98 \mathrm{~g} / \mathrm{mL} \\
\text { - asphaltene-to-resin ratio } 0.47 \\
\text { - apparent viscosity, } 45 \mathrm{cP} \text { at } \\
\text { day of emulsion formed and } 30 \\
\mathrm{cP} \text { a week later }\end{array}$ & $\begin{array}{l}\text { - entrained water stayed } \\
\text { as such condition for less } \\
\text { than one day } \\
\text { - water appeared as a } \\
\text { black liquid } \\
\text { - first day it has an } \\
\text { average water content } \\
\text { of about } 40 \% \text { and } \\
\text { reduced to around } 15 \% \\
\text { after one week } \\
\text { - viscosity } 2000-60000 \\
\text { cP } \\
\text { - density } 0.97 \text { - } 0.99 \\
\text { g/mL } \\
\text { - asphaltene-to-resin } \\
\text { ratio } 0.62 \text {; } \\
\text { - apparent viscosity, } 13 \\
\text { cP on day of emulsion } \\
\text { formed and } 3 \text { cP s a } \\
\text { week later. }\end{array}$ & $\begin{array}{l}\text { - indicates oil samples } \\
\text { that do not hold a } \\
\text { significant amount of } \\
\text { water, even when water } \\
\text { is present, it stays for a } \\
\text { very short period of time }\end{array}$ \\
\hline
\end{tabular}

Finally, varying the temperature caused changes in the emulsion stability, observed by phase inversion (changing to an $\mathrm{O} / \mathrm{W}$ emulsion) or by breakdown of the emulsions (resulting in coalescence). They also concluded that the average droplet diameter of $\mathrm{W} / \mathrm{O}$ emulsions depended greatly on the viscosity as well as the behavior of the emulsions, if they are Newtonian or non-Newtonian.

According to researchers (Fingas \& Fiellhouse, 2003, 2004; Wong \& Lim, 2015; Fingas, 2014), water-in-oil mixtures can be divided or grouped into four classes: stable water-in-oil emulsions, mesostable water-in-oil emulsions, entrained water, and unstable water-in-oil emulsions. The states of water-in-oil can be assigned to four classes by studying the stability, appearance, and rheological behavior of different water-in-oil samples (Table 1).

Characterization and properties of each type of emulsion have to be understood fully so that the type of emulsions, which are more relevant to the oil and gas industries, can be determined.
Johnsen and Rønningsen (2003) conducted experiments to study the viscosity of $\mathrm{W} / \mathrm{O}$ emulsions using different crude oil samples from the North Sea, ranging from light to heavy. The authors varied the temperature from $50{ }^{\circ} \mathrm{C}$ to 70 ${ }^{\circ} \mathrm{C}$, flow speed from $0.7 \mathrm{~m} / \mathrm{s}$ to $3 \mathrm{~m} / \mathrm{s}$, water cut from $0 \%$ to $90 \%$, and saturation and pressure from 12 bar to 100 bar. The results showed that although the viscosity range of the samples was very large, the changes in the relative viscosity of the W/O emulsions were very small for water cuts up to $70 \%$. In turn, for water cuts of $80 \%$ and $90 \%$, the relative viscosity changes were substantial.

Farah et al. (2005) studied the effect of volumetric fractions of the dispersed phase, temperature, and shear rate on the viscosity of W/O emulsions. They used six types of crude oils, with densities varying from $15^{\circ}$ to $40^{\circ} \mathrm{API}$, which were tested at temperatures from $8{ }^{\circ} \mathrm{C}$ to $50{ }^{\circ} \mathrm{C}$, with the disperse phase ranging from $0 \%$ to $40 \%$ and the shear rate from $10 \mathrm{~s}^{-1}$ to $80 \mathrm{~s}^{-1}$. The results indicated a Newtonian fluid behavior for the emulsions analyzed at the higher temperatures and 
containing the largest dispersed phase concentrations.

Dan and Jing (2006) carried out experiments of the viscosity of seven sets of W/O emulsions formed using light and heavy crude oils from different fields. The experimental conditions were processing temperature of $60{ }^{\circ} \mathrm{C}$ for the heavy oils and $30{ }^{\circ} \mathrm{C}$ for the light oils, water content ranging from $0 \%$ to $60 \%$, and shear rates varying between $15 \mathrm{~s}^{-1}$ and $600 \mathrm{~s}^{-1}$. The results showed that the W/O emulsions obtained with the oil of different densities behaved distinctly. The W/O emulsions formed using heavy oils showed non-Newtonian behavior, i.e., variation of viscosity with time. In contrast, the W/O emulsions formed with the light oils presented Newtonian behavior, i.e., unchanged viscosity.

Broboana and Balan (2007) analyzed the rheological behavior of W/O emulsions, using an asphaltic oil with water concentration of $30 \%$ and a paraffinic oil with water content of $6 \%$, both obtained from Romanian fields. The experiments were performed under a temperature of $5{ }^{\circ} \mathrm{C}$, at atmospheric pressure and shear rate ranging from $1 \mathrm{~s}^{-1}$ to $1000 \mathrm{~s}^{-1}$, using two rheometers (Anton Paar Physica models MC 300 and MC 1). Both samples presented non-Newtonian fluid behavior (pseudoplasticity).

Kumar and Mahto (2016) investigated the rheological behavior of W/O emulsions of a heavy crude oil sampled from a western oil field in India. The field was highly asphaltinic and waxy in nature, and it was potentially rich in resin fractions. Development of O/W emulsions caused considerable decrease in viscosity even at higher oil content, enabling emulsions to be easily transported through the pipes. The pour point of the heavy oil after emulsification was decreased greatly, permitting the oil to be transported through a pipeline under extremely low temperature conditions offshore. The addition of more surfactant in the aqueous phase decreased the droplet size of the emulsion and increased stability, although on the other hand it increased slightly the viscosity of the emulsion.

\subsection{Effect of emulsion viscosity reducers (EVRs)}

To overcome problems caused by emulsions, chemical products called emulsion viscosity reducers (EVRs) may be applied in the borehole. The lower viscosity makes the production process more efficient because the crude oil flows more easily (Husin et al., 2014).

EVRs belong to the class of chemicals that promote water-oil separation. These chemicals commonly are called demulsifiers. They are formulated specifically for down-hole injection through gas lift systems, capillary tubes or umbilicals in underwater operations. They are mixtures of oil-soluble polymers that have interfacial activity, by interacting with the natural emulsifiers at the oil-water interface (Allenson et al., 2011).

EVRs can be formed by poly(ethylene oxide)-bpoly(propylene oxide) block copolymers (PEO-PPO), ethoxylated phenols, alcohols, ethoxylated amines, ethoxylated resins, nonyl ethoxylated phenols, and sulfonic acid salts. These chemical products have a range of properties. Typically, they have a strong attraction for the oil-water interface, with the ability to destabilize the protective film around the droplets. They also have the ability to act as wetting agents, changing the contact angle of solids; and the ability to act as flocculants, promoting film drainage, thinning the interfacial film and inducing changes in the rheological properties, such as reduction of interfacial viscosity and elasticity (Ortiz et al., 2010; Daniel-David et al., 2005; Follotec et al., 2010).

The mechanism of interaction between EVRs and emulsifiers at the water-oil interface remains unclear. Nevertheless, the general effect of this interaction is to weaken the film around the droplets, allowing them to coalesce and form larger droplets (Ramalho et al., 2010).

Allenson et al. (2011) showed that EVRs weaken the film around the water droplets, making it easier for them to join into larger droplets. The result is a decline in drag forces, because of the reduction in the total surface area of the droplets and the number of interactions between them, which can transfer mechanical shear through the bulk phase of the fluid. The reduction in drag lowers the apparent viscosity.

The effect of lowering the viscosity of an emulsion by adding an EVR is illustrated in Figure 1. When the EVR is added to the emulsion, it migrates to the oil-water interface due to the interfacial 


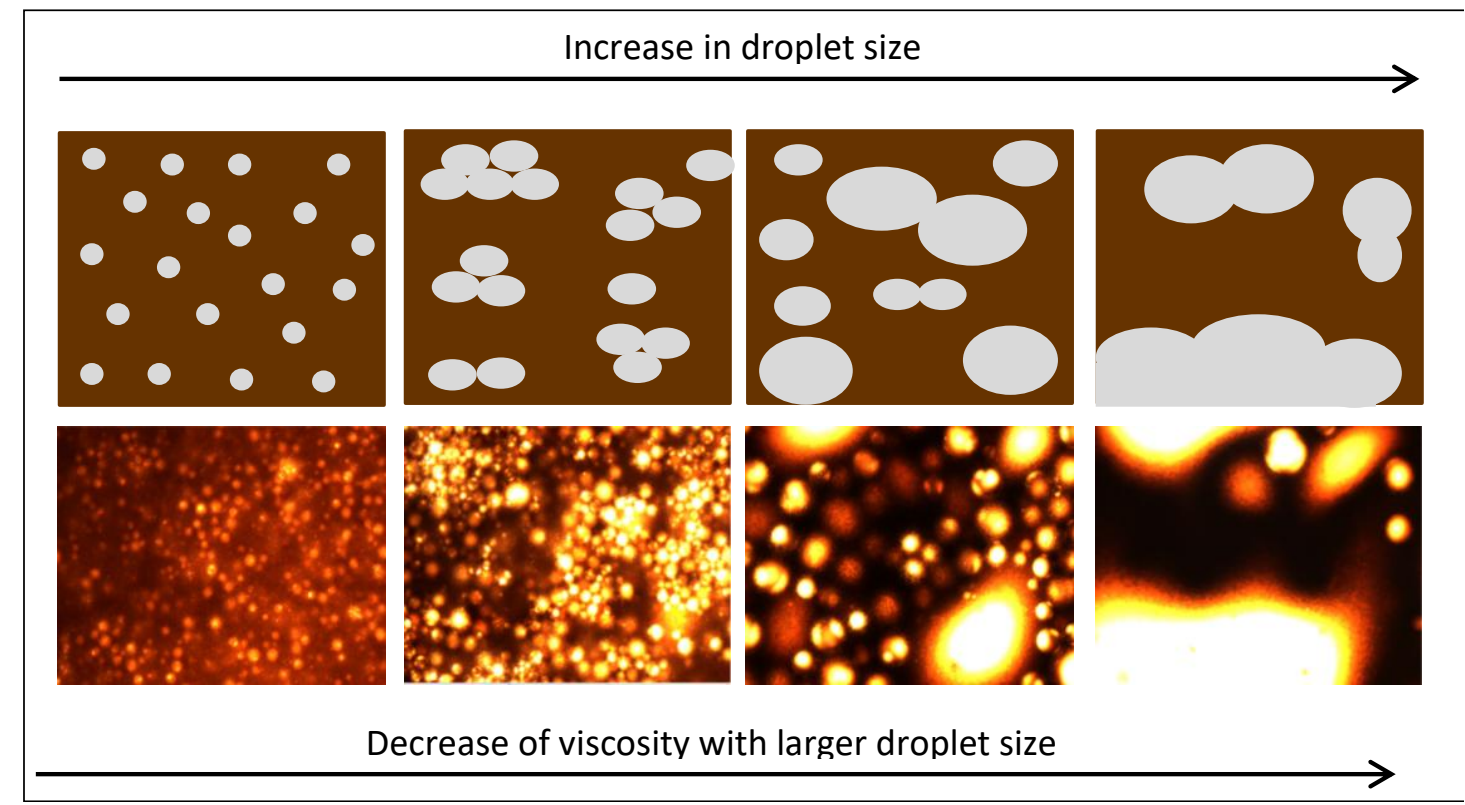

Figure 1. The addition of an EVR causes an increase in the size of the water droplets and reduction of the viscosity of emulsions.

activity, where it can interact or compete with the natural emulsifiers (such as asphaltenes). The water droplets start to aggregate and coalesce into larger droplets. Eventually, these droplets become too large and combine to form free water (continuous phase). During this process, the apparent viscosity continues to decline.

\subsection{Application of EVRs based on polymers}

The most suitable EVR for particular emulsion can be determined by bottle tests. In this test, different chemical products at different concentrations can be analyzed. This is important because different chemicals generate varied water droplet characteristics.

Allenson et al. (2011) observed that chemical EVRs with fast water drop activity, which promote faster breakdown of W/O emulsions, are normally considered good candidates for top-side treatment (demulsification treatment at the surface), but they can also have a negative effect when injected in deep wells with addition of gas lift. This happens because this type of EVR reduces the apparent viscosity of the fluid produced, but at the same time provokes premature separation of the emulsion, resulting in multi-phase fluids (water/oil/gas) that can clog production lines. Combination of bottle tests with rheological tests can identify the best EVR.
With respect to the chemical additives used, Zhang et al. (2006) observed efficiencies near 95\% for PEO-PPO-PEO triblock copolymers with different molar masses and PEO concentrations in demulsifying crude oil emulsions.

Some studies (Wu \& Xu, 2005; Xu et al., 2005; Zhang et al., 2004a,b) have shown that the demulsification performance of PEO-PPO block copolymers is correlated with the quantity of ethylene oxide (EO) and propylene oxide (PO) units in their structures.

$\mathrm{Xu}$ et al. (2005) also reported that the demulsification efficiency of commercial PEO-PPO triblock copolymers was higher for the copolymers with greater EO concentrations, since the PEO fraction in their structure forms the hydrophilic part of the demulsifier. They observed 100\% efficiency of demulsifiers containing $80 \%$ EO groups, but the one containing $10 \%$ EO units had no demulsification effect. The authors also studied the effect of isomerism of PEO-PPO triblock copolymers. These were called sequential (PEOPPO-PEO) and non-sequential (PPO-PEO-PPO). The different positions of the EO and $P O$ groups present in the structures changed the demulsifier's hydrophilic-lipophilic balance, interfacial properties and demulsification efficiency. For those with sequential structure, the two EO blocks at the ends were adsorbed in the water droplets, while the lipophilic part (PO) became oriented toward the oil 
phase, promoting weak steric repulsion, resulting in destabilization of the emulsion. The nonsequential copolymers (PPO-PEO-PPO) maintained the separation of the dispersed water droplets, retarding their coalescence.

\section{FINAL CONSIDERATIONS}

The increasing production of heavy and extraheavy crude oils in North America, South America and Eastern Asia, more technological innovation as well as research and development will be needed to generate specific solutions for crude oil transportation. These crude oils have high viscosity due the presence of components with high molecular weight. Furthermore, emulsified oils also have higher apparent viscosity, restricting flows through pipelines and impeding production.

In this review, technologies and methods to facilitate the transport of heavy and extra-heavy crude oils and emulsified oils from production sites to processing facilities were presented. The technologies currently in use, as well as new methods for this purpose, are based mainly on reduction of crude oil viscosity. These technologies promote many advantages, such as better flow in pipes, lower production costs, better equipment reliability and availability, and easier processing/refining.

One solution to enhance the flow rate is to reduce the apparent viscosity by using emulsion viscosity reducers (EVRs). This application relies on thorough testing and correct data interpretation to provide the correct chemical selection. The use of this technology has been demonstrated in several field applications in different locations around the world. Success can be measured by a variety of field parameters including flow rates, pump temperatures, and pressures.

\section{ACKNOWLEDGMENTS}

The authors of this review would like to thank Petrobras, the National Council for Scientific and Technological Development (CNPq), the Office for Improvement of University Personnel (CAPES), and the Rio de Janeiro State Research Support Foundation (FAPERJ) for the funding provided for this research.

\section{REFERENCES}

Abdel-Raouf, M. E.-S. Factors Affecting the Stability of Crude Oil Emulsions. Chapter 10. In: Abdel-Raouf, M. E.-S. Crude Oil EmulsionsComposition Stability and Characterization. Croatia: INTECH, ISBN 978-953-51-0220-5 2012. Available at: $<$ https://www.intechopen.com/books/crude-oilemulsions-composition-stability-andcharacterization/factors-affecting-the-stability-ofcrude-oil-emulsions>.

Acevedo, S.; Ranaudo, M.A.; Pereira, J.C.; Castillo, J.; Fernandez, A.; Perez, P.; Caetano, M. Thermo-optical studies of asphaltene solutions: evidence for solvent-solute aggregate formation Fuel, v. 78(9), p. 997-1003, 1999.

https://doi.org/10.1016/S0016-2361(99)00027-7

Allenson, S. J.; Yen, A. T.; Lang, F. Application of Emulsion Viscosity Reducers to Lower Produced Fluid Viscosity. Offshore Technology Conference, OTC-22443-MS, 4-6 October, Rio de Janeiro, Brazil, 2011. https://doi.org/10.4043/22443-ms

Al-Yaari, M.; Hussein, I. A.; Al-Sarkhi, A.; Abbad, M., Chang, F. Effect of water salinity on surfactantstabilized water-oil emulsions flow characteristics. Experimental Termal and Fluid Science, v.64, p. 54-61, 2015.

https://doi.org/10.1016/i.expthermflusci.2015.02.001

Anisa, A. N. I.; Nour, A. H. Affect of Viscosity and Droplet Diameter on water-in-oil (w/o) Emulsions: An Experimental Study. International Scholarly and Scientific Research \& Innovation, v. 4(2), p. 213216, 2010. https://doi.org/10.2118/79496-ms

Argiller, J.-F.; Coustet, C.; Henaut, I. Heavy oil rheology as a function of asphaltene and resin content and temperature. SPE International Thermal Operations and Heavy Oil Symposium and International Horizontal Well Technology Conference, SPE-79496-MS, 4-7 November, Calgary, Alberta, Canada 2002. https://doi.org/10.2118/79496-ms

Ariffin, T.S.T.; Yahya, E.; Husin, H. The rheology of light crude oil and water-in-oil-emulsion. Procedia Engineering, v.148, p. 1149-1155, 2016. https://doi.org/10.1016/j.proeng.2016.06.614 
Ashoori, S.; Sharifi, M.; Masoumi, M.; Salehi, M.M. The relationship between SARA fractions and crude oil stability. Egyption Journal of Petroleum, v. 26(1), p. 209-213, 2017.

https://doi.org/10.1016/i.ejpe.2016.04.002

Asomanung, S. Test methods for determining asphaltene stability in crude oils. Petroleum Science and Technology, v.21, p. 581-590, 2003. https://doi.org/10.1081/LFT-120018540

Azodi, M.; Nazar. A.R.S. An experimental study on factors affecting the heavy crude oil in water emulsions viscosity. Journal of Petroleum Science and Engineering, v.106, p.1-8, 2013.

https://doi.org/10.1016/i.petrol.2013.04.002

Broboana, D.; Balan, C. Investigations of the rheology of water-in-crude oil emulsions. Scientific Bulletin - University Politehnica of Bucharest, Series B, v. 69(3), p. 35-50, 2007.

Castro, L. V.; Flores, E.A.; Vazquez, F. Terpolymers as flow improvers for Mexican crude oils. Energy \& Fuels, v. 25(2), p. 539-544, 2011. https://doi.org/10.1021/ef101074m

Castro, L. V.; Vazquez, F. Fractionation and characterization of Mexican crude oils. Energy \& Fuels, v.23, p. 1603-1609, 2009.

https://doi.org/10.1021/ef8008508

Dan, D.; Jing, G. Apparent viscosity prediction of non-Newtonian water-in-crude oil emulsions. Journal of Petroleum Science and Engineering, v. 53 (1-2), p. 113-122, 2006.

https://doi.org/10.1016/i.petrol.2006.04.003

Daniel-David, D.; Pezron, I.; Dalmazone, C.; Noik, C.; Clausse, D.; Komunjer, R. Elastic properties of crude oil/water interface in presence of polymeric emulsion breakers. Colloids and Surface: A Physicochemical Engineering Aspects, v. 270-271, p. 257-262, 2005.

https://doi.org/10.1016/i.colsurfa.2005.06.010

Duan, L.; Jing, J.; Wang, J. Study on phase inversion characteristics of heavy oil emulsions. The Twentieth International Offshore and Polar Engineering Conference, ISOPE-I-10-364, 20-25 June, p. 83-87, 2010.

Dusseault, M. B.; Shafiei, A. Oil sands. Countries OotPE. World oil outlook., 2011. Available at: <http://onlinelibrary.wiley.com/doi/10.1002/1435 6007.a26_129.pub2/abstract>.
Farah, M. A.; Oliveira, R. C.; Caldas, J. N.; Rajagopal, K. Viscosity of water-in-oil emulsions: Variation with temperature and water volume fraction. Journal of Petroleum Science and Engineering, v. 48 (3-4), p. 169-184, 2005. https://doi.org/10.1016/j.petrol.2005.06.014

Fenistein, D.; Barré, L.; Broseta, D.; Espinat, D.; Livet, A.; Roux, J.-N.; Scarsella, M. Viscosimetric and neutron scattering study of asphaltene aggregates in mixed toluene/heptane solvents. Langmuir, v. 14(5), p. 1013-1020, 1998.

https://doi.org/10.1021/la9709148

Fingas, M. F. Water-in-oil emulsions: Formation and prediction. Journal of Petroleum Science and Engineering, v. 3(1), p. 38-49, 2014.

https://doi.org/10.1002/9781118989982.ch8

Fingas, M.; Fieldhlur, B. Formation of water-inoil emulsions and application to oil spill modelling. Journal of Hazardous Materials, v. 107(1-2), p. 3750, 2004.

https://doi.org/10.1016/j.jhazmat.2003.11.008

Fingas, M.; Fieldhouse, B. Studies on crude oil and petroleum product emulsions: Water resolution and rheology. Colloids and Surfaces A: Physicochemical and Engineering Aspects, V. 333(1-3), p. 67-81, 2009.

https://doi.org/10.1016/j.colsurfa.2008.09.029

Fingas, M.; Fielhouse, B. Studies of the formation process of water-in-oil emulsions. Marine Poluation Bulletin, v. 47(9-12), p. 369-396, 2003. https://doi.org/10.1016/S0025-326X(03)00212-1

Follotec, A. L.; Pezron, I.; Noik, C.; Dalmazzone, C.; Komunjer, L. M. Triblock copolymers as destabilizers of water-in-crude oil emulsions. Colloids and Surfaces A: Physicochemical Engineering Aspects, v.365 (1-3), p. 162-170, 2010. https://doi.org/10.1016/i.colsurfa.2010.02.025

Garcia-Olvera, G.; Reilly, T. M.; Lehmann, T. E.; Alvarado, V. Effects of asphaltenes and organic acids on crude oil-brine interfacial visco-elasticity and oil recovery in low-salinity waterflooding. Fuel, v.185, p. 151-163, 2016.

https://doi.org/10.1016/i.fuel.2016.07.104

Ghanavati, G.; Shojaei, M.-J.; Ramazani, A.S.A. Effects of asphaltene content and temperature on viscosity of Iranian heavy crude oil: Experimental and modeling study. Energy Fuels, v. 27(12), p. 7217-7232, 2013. https://doi.org/10.1021/ef400776h 
Ghannam, M. T.; Esmail, N. Flow enhancement of medium-viscosity crude oil. Petroleum Science and Technology, v.24, p. 985-999, 2006.

https://doi.org/10.1081/LFT-200048166

Guo, K.; Li, H.; Yu, Z. In-situ heavy and extraheavy oil recovery: A review. Fuel, v. 185, p. 886902, 2016. https://doi.org/10.1016/i.fuel.2016.08.047

Haeght. T.; Ellingsen, T. The effect of Breaking Waves On Oil Spills: 1. Emulsification of crude Oil at Sea, Publication of SINTEF, The Foundation of Scientific and Industrial Research at The University of Trondheim, Norway, p. 23, 1977. Available at: <https://www.sintef.no/globalassets/project/jip_oil_in_i ce/dokumenter/publications/jip-rep-no-11-dispersanteffectiveness-in-arctic-conditions-150207.pdf>.

Hasan, S. W.; Ghannam, M. T.; Esmail, N. Heavy crude oil viscosity reduction and rheology for pipeline transportation. Fuel, v. 89(5), p. 10951100, 2010. https://doi.org/10.1016/j.fuel.2009.12.021

Henaut, I.; Barre, L.; Argillier,J. F.; Brucy, F.; Bouchar, R. SPE International Symposium on Oilfield Chemistry, SPE-65020-MS, 13-16 February, Houston, Texas, 2001.

Henaut, I.; Forestiere, A.; Heraud, J. P.; Argillier, J. F. Method of Optimizing Heavy Crude Transportation by Incorporation Under Pressure of Dimethyl Ether. US Patent Application, 2007.

Available at:

<https://www.google.ch/patents/US20070295642>.

Hoshyargar, V.; Ashafizadeh, S. N. Optimization of flow parameters of heavy crude oil-in-water emulsions through pipelines. Industrial and Engineering Chemistry Research, v. 52(4), p. 16001611, 2013. https://doi.org/10.1021/ie302993m

Husin, H.; Azizi, A.; Husna, A. An overview of viscosity reducers in heavy crude oil production. Chemeca, p. 1246-1253, 2014.

Johsen, E. E.; Ronningsen, H. P. Viscosity of 'live' water-in-crude-oil emulsions: experimental work and validation of correlations. Journal of Petroleum Science and Engineering, v. 38(1-2), p. 23-36, 2003.

https://doi.org/10.1016/50920-4105(03)00020-2

Junaki, E.; Ghanaatian, S.; Zargar, G. A new approach to simultaneously enhancing heavy oil recovery and hindering asphaltene precipitation. Iranian Journal of Oil \& Gas Science and Technology, v. 1(1), p.37-42, 2012.
Kelesoglus, S.; Pettersen, B. H Sjoblom, J. Flow properties of water-in-North Sea heavy crude oil emulsions. Journal of Petroleum Science and Engineering, v.100, p. $14-23,2012$. https://doi.org/10.1016/i.petrol.2012.11.006

Kessick, M.A.; Denis,G.E.S. Pipeline Transportation of Heavy Crude Oil. US Patent 4,343,323, August 10, 1982. Available at: <https://docs.google.com/viewer?url=patentimage s.storage.googleapis.com/pdfs/US4343323.pdf>.

Kumar, S.; Mahto, V. Emulsification of Indian heavy crude oil in water for its efficient transportation through offshore pipelines. Chemical Engineering Research and Design, v. 115, p. 34-43, 2016.

https://doi.org/10.1016/j.cherd.2016.09.017

Kuzmic, A. E.; Radosevic, M.; Bogdanic, G.; Srica, V.; Vukovic, R. Studies on the influence of long chain acrylic esters polymers with polar monomers as crude oil flow improver additives. Fuel, v. 87(1314), p. 2943-2950, 2008.

https://doi.org/10.1016/i.fuel.2008.04.006

Langevin, D.; Poteau, S.; Henaut, I.; Argillier, J. F. Crude oil emulsion properties and their application to heavy oil transportation. Oil \& Gas Science and Technology, v. 59, p. 511-521, 2004. https://doi.org/10.2516/ogst:2004036

Li, H.Y.; Zhang, J.J.; Song, C.F.; Sun, G.Y. Journal of Petroleum Science and Engineering, v.135, p. 476-483, 2015.

https://doi.org/10.1016/i.petrol.2015.10.010

Luo, P.; Gu, Y. Effects of asphaltene content and solvent concentration on heavy oil viscosity. SPE International Thermal Operations and Heavy Oil Symposium, SPE-97778-MS, 1-3 November, Calgary, Alberta, Canada, 2005. https://doi.org/10.2118/97778-ms

Maia Filho, D.C.; Ramalho, J. B. V. S.; Spinelli, L. S.; Lucas, E. F. Aging of water-in-crude oil emulsions: Effect on water content, droplet size distribution, dynamic viscosity and stability. Colloids and Surfaces A: Physicochemical Engineering Aspects, v. 396, p. 208-212, 2012. https://doi.org/10.1016/j.colsurfa.2011.12.076 
Martinez-Palou, R.; Mosqueira, M. L.; ZapataRendón, B.; Mar-Juárez, E.; Bernal-Huicocheca, C.; La Cruz, J.; Aburto, J. Transportation of heavy and extra-heavy crude oil by pipeline: A review. Journal Petroleum Science Engineering, v. 75(3-4), p. 274282, 2011.

https://doi.org/10.1016/i.petrol.2010.11.020

Martinez-Palou, R.; Reyes, J.; Ceron-Camacho, R.; Ramirez-Santiago, M.; Villanueva, D.; Vallejo, A. A.; Aburto, J. Study of the formation and breaking of extra-heavy-crude-oil-in-water emulsions-A proposed strategy for transporting extra heavy crude oils. Chemical Engineering and Processing, v.98, p. 112-122, 2015.

https://doi.org/10.1016/i.cep.2015.09.014

Muraza, O.; Galadima, A. Aquathermolysis of heavy oil: $A$ review and perspective on catalyst development. Fuel, v.157, p. 219-231, 2015. https://doi.org/10.1016/i.fuel.2015.04.065

Nunez, G. A.; Sanchez, G.; Gutierrez, X.; Silva, F.; Dalas, C.; Rivas, H. Rheological behavior of concentrated bitumen in water emulsions. Langmuir, v. 16(16), p. 6497-6502, 2000.

https://doi.org/10.1021/la990412p

Ortiz, D. P.; Baydak, E. N.; Yarranton,H. W. Effect of surfactants on interfacial films and stability of water-in-oil emulsions stabilized by asphaltenes. Journal of Colloid and Interface Science, v. 351(2), p. 542-555, 2010.

https://doi.org/10.1016/i.jcis.2010.08.032

Ovalles, E.; Rogel, E.; Morazan, H.; Moir, M. E. Synthesis, characterization, and mechanism of asphaltene inhibition of phosphopropoxylated asphaltenes. Fuel, v.180, p. 20-26, 2016. https://doi.org/10.1016/i.fuel.2016.03.084

Plasencia, J.; Pettersen, B.; Nydal, O. J. Pipe flow of water-in-crude oil emulsions: Effective viscosity, inversion point and droplet size distribution. Journal of Petroleum Science and Engineering, v. 101, p.35-45, 2013.

https://doi.org/10.1016/i.petrol.2012.11.009

Ramalho, J. B. V. S.; Lechuga, F. C.; Lucas, E. F. Effect of the structure of commercial poly(ethylene oxide-b-propylene oxide) demulsifier bases on the demulsification of water-in-crude oil emulsions: elucidation of the demulsification mechanism. Química Nova, v. 33(8), p. 1664-1670, 2010. https://doi.org/10.1590/S0100-40422010000800009
Sanchez, L. E.; Zakin, J .L. Transport of viscous crudes as concentrated oil-in-water emulsions. Industrial \& Engineering Chemistry Research, v. 33(12), p. 3256-3261, 1994.

https://doi.org/10.1021/ie00036a047

Saniere, A.; Henauti, I.; Argillier, J. F. Pipeline transportation of heavy oils, a strategic, economic and technological challenge. Oil \& gas science and technology, v. 59(5), p. 455-466, 2004. https://doi.org/10.2516/ogst:2004031

Sefton, E.; Sinton, D. Evaluation of selected viscosity prediction models for water in bitumen emulsions. Journal of Petroleum Science and Engineering, v. 72(1-2), p. 128-133, 2010. https://doi.org/10.1016/j.petrol.2010.03.010

Shecaira, F. S.; Branco, C. C. M.; Souza, A. L. S.; Pinto, A. C. C.; Holleben, A. R. C.; Johann, P. R. S. IOR: The Brazilian Perspective. SPE/DOE Improved Oil Recovery Symposium, SPE-75170-MS, 13-17 April, Tulsa, Oklahoma, 2002.

Sheng, J. J. Status of surfactant EOR technology. Petroleum, v. 1(2), 97-105, 2015. https://doi.org/10.1016/i.pet/m.2015.07.003

Sheu, E. Y.; Detar, M. M.; Storm, D. A. Rheological properties of vacuum residue fractions in organic solvents. Fuel, v.70, p. 1151-1156, 1991a. https://doi.org/10.1016/0016-2361(91)90236-4

Sheu, E. Y.; Storm, D. A.; De Tar, M. M. Asphaltenes in polar solvents. Journal of NonCrystalline solids, v. 131(Part 1), p. 341-347, 1991b. https://doi.org/10.1016/0022-3093(91)90326-2

Soni, H. P.; Kiranbala, A.; Agrawal, K.S.; Nagar, A.; Bharambe, D. P. Designing maleic anhydride- $\alpha$ olifin copolymeric combs as wax crystal growth nucleators. Fuel Processing Technology, v. 91(9), p. 997-1004, 2010.

https://doi.org/10.1016/j.fuproc.2010.02.019

Sullivan, A. P.; Kilpatrick, P. K. The effects of inorganic solid particles on water and crude oil emulsion stability. Industrial \& Engineering Chemistry Research, v. 41(14), p. 3389-3404, 2002. https://doi.org/10.1021/ie010927n

Varfolomeev, M. A.; Galukhin, A.; Nurgaliev, D. K.; Kok, M. V. Thermal decomposition of Tatarstan Ashal'cha heavy crude oil and its SARA fractions. Fuel, v.186, p. 122-127, 2016. https://doi.org/10.1016/i.fuel.2016.08.042 
Wang, H.; Huang, C. P. The effect of turbulence on oil emulsification. The Physical Behavior of Oil in the Marine Environment Workshop. Princeton University, Princeton, New Jersey, p. 81-100, 1979.

Wang, W.; Wang, P.; Lik, K.; Duan, J, Wu, K.; Gong, J. Prediction of the apparent viscosity of nonNewtonian water-in-crude oil emulsions. Petroleum exploration and development, v. 40(1), p. 130-133, 2013.

Wong, S. F.; Lim, J. S.; Dol, S. S. Crude oil emulsion: A review on formation, classification and stability of water-in-oil emulsions. Journal of petroleum Science and Engineering, v.135, p. 498504, 2015. https://doi.org/10.1016/j.fuel.2016.08.042

Wu, J.; Xu, Y.; Dabros, T.; Hamza, H. Effect of EO and $P O$ positions in nonionic surfactants on surfactant properties and demulsification performance Colloids and Surfaces A: Physicochemical Engineering Aspects, v. 252(1), p. 79-85, 2005.

https://doi.org/10.1016/j.colsurfa.2004.09.034

Xie, H.; Zhang, F.; Dong, L. Study and application of the viscosity reducer used in production of the viscous crude oil. SPE International Symposium on Oilfield Chemistry, SPE-65382-MS, 13-16 February, Houston, Texas, 2001. https://doi.org/10.2118/65382$\underline{\mathrm{ms}}$
Xu, Y.; Wu, J.; Dabros, T.; Hamza, H. Optimizing the polyethylene oxide and polypropylene oxide contents in diethylenetriamine-based surfactants for destabilization of a water-in-oil emulsion. Energy \& Fuels, v. 19(3), p.916-921, 2005. https://doi.org/10.1021/ef0497661

Yaghi, B. M.; Al-Bemani, A. Heavy Crude Oil Viscosity Reduction for Pipeline Transportation. Energy Sources, v.24, p.93-102, 2002. https://doi.org/10.1080/00908310252774417

Yudin,I. K.; Nikolaenko,G. L.; Gorodetskii, E. E.; Kosov, V. I.; Melikyan, V. R.; Markhashov, E. L.; Frot, D.; Briolant, Y. Mechanisms of asphaltene aggregation in toluene-heptane mixtures Journal of Petroleum Science and Engineering, v. 20(3-4), p. 297-301, 1998. https://doi.org/10.1016/S09204105(98)00033-3

Zhang, Z.; Xu, G. Y.; Wang, F.; Dong, S. L.; Li, Y. $M$. Characterization and demulsification of poly(ethylene oxide)-block-poly(propylene oxide)block-poly(ethylene oxide) copolymers. Journal of Colloid and Interface Science, v. 277(2), p. 464470, 2004a.

Zhang, Z.; Xu, G.; Wang, F.; Dong, S.; Chen, Y. Demulsification by amphiphilic dendrimer copolymers. Journal of Colloid and Interface Science, v. 282(1), p.1-4, 2004b. https://doi.org/10.1016/j.jcis.2004.08.144 